\title{
A Study of Longwave Radiation Codes for Climate Studies: Validation with ARM Observations and Tests in General Circulation Models
}

\author{
DOE Grant DEFG0294ER61746 \\ Final Report \\ Robert G. Ellingson \\ Professor Emeritus \\ University of Maryland \\ College Park, MD 20742 \\ Current Affiliation \\ Department of Meteorology \\ Professor and Department Chair \\ Florida State University \\ Tallahassee, Fl 32306
}

\section{Project Summary}

Research by the international climate community has shown that uncertainty associated with the interaction between clouds and radiation is the single most important factor determining the magnitude of possible climatic responses to human activity. Consequently, DOE launched a major initiative - the Atmospheric Radiation Measurements (ARM) Program - directed at improving the parameterization of the physics governing cloud and radiative processes in global climate models (GCMs).

One specific goal of ARM is to improve the treatment of radiative transfer in GCMs under clearsky, general overcast and broken cloud conditions. In 1990, 1993 and again in 1996, we proposed a program to contribute to this goal by attacking major problems connected with one of the dominant radiation components of the problem - longwave radiation (i.e. wavelengths $>3 \mu \mathrm{m})$. The long-term research objectives of this program were to:

- develop an optimum longwave radiation model for use in GCMs that has been calibrated with state-of-the-art observations,

- assess the impact of the longwave radiative forcing in a GCM,

- determine the sensitivity of a GCM to the radiative model used in it, and

- determine how the longwave radiative forcing contributes relatively when compared to shortwave radiative forcing, sensible heating, thermal advection and expansion.

Our approach to developing the radiation model has been to test existing models in an iterative, predictive fashion. The model-observation differences have been used to develop new models to be tested with new data. Similarly, our GCM studies used existing GCMs to study the radiation sensitivity problem. We anticipated that the outcome of this approach would provide both a better longwave radiative forcing algorithm and a better understanding of how longwave radiative forcing influences the equilibrium climate of the atmosphere. 
The research activities took place in two general categories, namely: (1) Radiation Model Testing Activities (led by Prof. Robert Ellingson), and (2) General Circulation Model Testing Activities (led by Prof. Ferdinand Baer). The research under (2) ended in 1996 following the review of our then renewal proposal and the continuing research focused on (1) - Radiation Model Testing Activities.

Under(2), the first three years were spent comparing various longwave radiation models (LWRMs) taken from operating GCMs with one-another primarily with clear sky data. Additionally, data from archived GCM runs using different algorithms were collected. The next three years were spent completing the LWRM intercomparison under cloudy sky conditions and referencing the results to a line-by-line model. In addition, we analyzed archived GCM data to determine climate prediction sensitivity to various longwave radiative heating features. Finally, we reconfigured a GCM with a different LWRM algorithm and ran companion integrations of the same model with two different algorithms to establish carefully controlled intercomparisons.

Under (1), the first three years of the project were spent gathering different longwave radiation models (LWRMs), determining the sensitivity of the calculations to uncertainties in the meteorological data, determining whether the uncertainties in the observations will allow us to distinguish between the different models, and determining approaches for using the observations and various models for determining certain cloud properties. The next three years (1993-96) focused on comparing longwave observations with model calculations, developing new cloudradiation models and comparing the new models with observations from the ARM sites. Most of our research efforts during the period from (1997-2004) were spent on developing and testing new models of the three-dimensional effects of cumulus clouds on longwave radiation, including the interpretation of cloud observations.

In 2002, Prof. Ellingson moved from the University of Maryland to the Florida State University where this project continues under a separate grant. However, two Ph.D. degrees seeking students performing research under this project remained at Maryland. We are very appreciative of the DOE to allow no-cost extensions of this project under Prof. Ellingson's direction as a Professor Emeritus at Maryland, thereby allowing these students to complete their Ph.D. research.

Several substantial achievements have been made by this project, as will be summarized in a later section. We are quite confident that we now have a strong grip on the modeling of clear-sky radiation and broken, liquid-water clouds. However, these models, particularly those for broken cloudiness, have not been stressed over a wide range of data, and the sensitivity of GCM models to cloudiness parameterizations have not yet been performed. Nevertheless, we believe we are now at the brink of being able to reliably stress the models over a wide range at the level of a few $\mathrm{W} \cdot \mathrm{m}^{-2}$ because of the completion of the basic instrumentation at the Southern Great Plains (SGP) Clouds and Radiation Testbed (CART) site (i.e., operational Raman lidar, cloud radar, more thorough characterization of the AERI, the water vapor IOPs, etc.), and because of the data expected from the Tropical Western Pacific (TWP) and North Slope of Alaska (NSA) sites. Thus, we are now poised to deliver on ARM's promise of making substantial improvements to radiation models and to begin serious testing of radiation-cloud models in GCMs.

This project has been carried out by the PI working with graduate students, postdoctoral research associates, and other members of the ARM community. As the project has progressed, many publications and presentations have resulted. Since a summary report was prepared as part of the 
proposal review process in 1996, this report focuses on the period from 1996 through 2004. Table 1 provides a summary of the major project related science activities during this period. A summary of the most important accomplishments in bulletized form is given in a later section.

\begin{tabular}{|l|c|}
\hline \multicolumn{1}{|c|}{ Table 1. - Summary of ARM-related science activities April 1996 - June 2004. } \\
\hline \multicolumn{1}{|c|}{ Category } & Number \\
\hline Publications & 16 \\
\hline In refereed journals & 3 \\
\hline In preparation for refereed journals & 40 \\
\hline Conference proceedings and reports & 65 \\
\hline Presentations (1996-2004) & \\
\hline ARM-related Workshops (1996-2001) & 9 \\
\hline Organized & 18 \\
\hline Attended & 7 \\
\hline Graduate Students Supported/advised & 7 \\
\hline M.S. Degrees completed & 4 \\
\hline Ph.D. Degrees completed & 4 \\
\hline Postdoctoral Advisees & \\
\hline
\end{tabular}

Note that the PI has been very active in participating in meetings of ARM Science Team working groups, the Science Team Executive Committee and the ARM-UAV program where he has provided technical oversight to the program and helped in planning future activities. Furthermore, Prof. Ellingson has assumed a leadership role in many ARM activities, including: (1) member and chair (1995-2004), Science Team Executive Committee (STEC), (2) missionscientist for the ARM/UAV Program (1994 - 2003), (3) co-author of the ARM Science Plan (DOE, 1996), and (4) hosting and chairing IRF workshops. A detailed listing of all publications, presentations, graduate student papers and dissertations, and ARM Science Team activities is given below.

\section{Major Research Accomplishments - Summary Form - 1996-2001}

- Developed a generalized technique for calculating the effective cloud fraction $\mathrm{N}_{\mathrm{e}}$ for random rectangular pyramids and used it to explain the sensitivity of $\mathrm{N}_{\mathrm{e}}$ to variations in aspect ratio, distribution of cloud sizes, gappiness on the horizontal plane, and inclination of the cloud sides (see Han and Ellingson, 1999).

- Used ARM SGP pre-MMCR observations of cumulus clouds in an attempt to validate several different longwave cloudiness models (Han and Ellingson, 2000). The observations show the general form of the models to be correct, but there were insufficient observations covering a wide range of aspect ratios or for cloud fractions in the 0.5- 0.9 range to distinguish between different models.

- Developed an empirical narrow band model for water vapor covering the $0-3000 \mathrm{~cm}^{-1}$ interval and calibrated it with a detailed line-by-line (LBLRTM) model (Warner and Ellingson, 2000), thereby allowing for rapid, accurate calculations for use in interpretation of observations and or cloud-related studies. 
- Developed a graphical user interface for the narrow band model noted above (see Ellingson and Takara, 2000) that allows the user to specify the atmospheric parameters, to save selected numerical output, to perform sensitivity analyses, and to graphically portray the results of the calculations.

- Contributed to the IRF-led AERI-QME that led to one of ARM's primary accomplishments the demonstration that longwave flux at the surface may be calculated to within $5 \mathrm{~W} \cdot \mathrm{m}^{-2} \mathrm{rms}$ (see Ellingson, 1998; Turner et al., 2004).

- Contributed to the identification (Ellingson et al., 1999) and first attempts at solution (Tobin

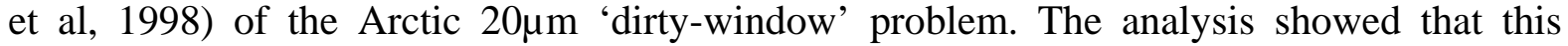
window is important to the heat budget because of the low temperatures and small columnar water in the Arctic. The new observations showed the poor performance of the existing models and have led to new formulations of the continuum in this region.

- Examined the role of multiple scattering on the transfer of longwave radiation in broken cloud fields using Monte Carlo simulations (Takara and Ellingson, 1996, 1999) and documented the range of cloud radiative parameters where scattering could play an important role.

- Led several field deployments of the ARM-UAV program as mission scientist that demonstrated the capability of the UAV as a radiation measurement platform (Valero et al., 1996), as a platform for studying the diurnal cycle of radiation, and as a platform for studying cirrus clouds (Stephens et al., 2000).

- Discovered large discrepancies between pyrgeometer/AERI inferred and theoretical estimates of effective longwave cloud fraction for many broken cumulus cases at the SGP (Cheng, 1999; Ellingson, Cheng and Takara, 2001).

- Applied the MM5 mesoscale model at $1 \mathrm{~km}$ resolution to NOAA data during the July 1997 SCM IOP to test the combined adequacy of the model and data for 24 hour predictions of the daily downwelling surface solar radiation at the SGP site (i.e., a gross test of the cloud parameterization and forecast - see Armstrong, 2000). The results show that the MM5 underestimated the daily-averaged shortwave flux by about $45 \mathrm{~W} \cdot \mathrm{m}^{-2}$, although values as large as $300 \mathrm{~W} \cdot \mathrm{m}^{-2}$ were obtained. The results are in general agreement with a similar study conducted with the Eta regional model by Hinkelman and Ackerman (1998), and highlight the need to study the cloud formation and radiation parameterizations used in mesoscale models..

- Worked with IRF working group to define a broadband QME for testing GCM radiation parameterizations. The basis for this QME are being implemented in an on-going ARM project led by to calculated the vertical distribution of short-and-long-wave fluxes and heating rates over the SGP central facility for one SCM IOP as the IRF contribution to a joint IRF-CMP-CP working group project to develop a CD with extensive ARM observations and model results (BBHRP).

- Developed an IDL procedure for estimating the probability of clear line of sight through the atmosphere from cloud imagery data for use in validating/developing techniques for including finite sized cloud effects on longwave transfer (Ma, 2001).

- Discovered a theoretical improvement for including finite sized cloud effects on longwave fluxes and cooling rates (Ma, 2001, 2004). 
- Used cloud resolving and large eddy simulation model results to develop and evaluate a general sampling strategy for estimating the probability of a clear line of sight (PCLOS) through cumulus a cloud layer using data from the whole sky and total sky imager (see dissertation by Ma, 2004). This strategy depends upon the frozen turbulence hypothesis, wind speed, cloud correlation length and transect length to define an optimum sampling interval.

- Using the noted strategy, tested a variety of PCLOS models with SGP ARM cloud imagery using a variety of ancillary ARM observations to show the range of agreement between observations and the PCLOS models for cumulus clouds at the SGP. Overall, the geometrical effects of small cumulus clouds at the SGP appear to be parameterizable with simple analytic functions - Poisson distributed hemispheres.

- Showed that at the SGP, the cloud side effects of small cumulus are small - the order of a few $\mathrm{W} \mathrm{m}^{-2}$ - but not negligible. Larger effects are extected in the tropics, and we plan to apply our sampling strategy to data from the Tropical Western Pacific sites to study this problem.

- Developed a procedure for using the intensity of individual stars in nighttime Whole Sky Imager (WSI) data to estimate broadband atmospheric extinction (Musat, 2000) and aerosol optical depth (AOD) as a function of time (see dissertation by Musat, 2004).

- Using data from 307 clear nights, compared WSI inferred AODs to simultaneous estimates from the Raman lidar and to daytime Cimel photometry. The results show very good agreement in both AOD and temporal variation, thereby establishing the WSI as a suitable candidate for aerosol monitoring at night and in remote locations. The results from the WSI analysis can now be used to improve the WSI nighttime cloud retrievals, thereby possibly extending our knowledge of nighttime cloudiness, an important parameter for understanding observations and calculations during the nighttime.

\section{Participation in ARM Science Team Activities}

1. Chair, ARM Science Team Executive Committee, activities of which have included:

- organizing and leading the order of three meetings of this group per year

- providing scientific advice regarding the ARM the U.S. Department of Energy

- designing and organizing the annual AST meeting,

- Representing the ARM Science Team at several AMT/ACT meetings

2. ARM-UAV Mission Scientist, duties have included:

- Organizing UAV Science Team meetings and contributions to science plans for deployments (see reports below and http://armuav.atmos.colostate.edu/armuav2.html)

- Leading field deployments (Spring 96, Fall 96, Fall 97, and Spring 99) see http://armuav.atmos.colostate.edu/armuav.html

- Making presentations and writing papers regarding the field deployments

- Making presentations to the Washington Area Group in 1997 as part of their review of ARM 
3. Chair, IRF Working Group, activities of which have included:

- Organizing and co-chairing IRF Workshops. (Univ. of Maryland, Jan. 1997, Jan. 1998; Suny Albany, Oct. 1999 w. Joe. Michalsky, Richland, WA, Oct. 2001)

- Organizing, with Ric Cederwall, the ARM IRF, Cloud and SCM Working Group Workshop (Oct. 1998)

- Delivering a presentation to the 1997 ARM Science Team meeting that summarized IRF accomplishments from the start of ARM

- Writing a white paper for the STEC summarizing the state of the IRF (July 2000, see above and http://www.arm.gov/docs/research.html\#vision2000)

- Organizing the IRF steering committee (Oct. 2000)

- Representing IRF (and ARM) at other working group meetings including:

- Cloud Properties Working group, 16-18 June 1997, Boulder, CO

- SCM Workshop, October 1999

- WCRP GEWEX Radiation Panel - July 1996, Dublin, Ireland; July 1997, Honolulu, HI; Sept. 1998, St. Andrews, Scotland; Sept. 1999, GISS, New York, NY.

4. Mission Scientist, The second ARM Enhanced Shortwave Experiment (ARESE II)

- Organizing workshops to plan ARESE II (Oct 1998 and March 1999),

- Organizing contributions to science plan (see reports below),

- Leading field deployments Feb. - April 2000 (see http://armuav.atmos.colostate.edu/uavw00/uavw00.html),

- Organizing meetings of the UAV Science Team - Oct. 2000 and Feb. 2001, and

- Making presentations and writing papers regarding the field deployments at a DOE review of the UAV program in Washington, DC in April 2000, the 2001 ARM Science Team Meeting, at IAMAS 2001, at the Aug 2001Chapman Conference, and at a Jan 2002 DOE review in Washington, DC (see below).

5. Participant, IRF Working group, activities of which have included:

- Developing, with Tony Clough and several others, a new QME for testing climate model radiation codes for clear and overcast conditions.

6. Participant, Cloud Properties Working Group, activities of which have included:

- Attending and participating in workshops, (June 1997, Feb. 1998, Dec. 1999, Jan. 2001)

7. Member, North Slope of Alaska Site Advisory Panel, activities of which have included:

- Attending meetings of the panel in March 1997, 1998.

- Reviewing and contributing to panel reports

8. Chair, InterComparison of Radiation Codes in Climate Models (ICRCCM), relevant ARM activities included:

- Planning and helping develop Phase III of the solar portion of ICRCCM. This plan was developed through a workshop hosted by Ellingson at the University of Maryland on 1 February 1999. In attendance were R. G. Ellingson, Howard Barker, V. Ramaswamy (GFDL), Rangasayi Halthore (BNL). The final plan for this may be found at http://reef.atmos.colostate.edu/icrccm/.

- Helping plan and proving web page assistance for the I3RC project (see http://climate.gsfc.nasa.gov/I3RC/) 


\section{Publications}

\section{a. Refereed journal articles}

Baer F., N. Arsky, J. J. Charney, and R. G. Ellingson, 1996: Sensitivity of heating rates from global climate model radiation codes. J. Geophys. Res., 101, D21, 26589-26603.

Baer F., N. Arsky, J. J. Charney, and R. G. Ellingson, 1996: Sensitivity of heating rates from global climate model radiation codes. J. Geophys. Res., 101, D21, 26589-26603.

Ellingson, R. G. And W. J. Wiscombe, 1996: The spectral radiance experiment (SPECTRE): Project description and sample results. Bull. Amer. Meteor. Soc., 77, 1967-1985.

Ellingson, R. G., 1997: Preface to Satellite data applications: Weather and climate. Adv. Space Res.,19, 405-406.

Ellingson, R. G., K. Stamnes, J. A. Curry, J. E. Walsh, B. D. Zak, 1999: Overview of North Slope of Alaska/Adjacent Arctic Ocean Science Issues. J. Climate , 12, 46-63

Han., D. and R. G. Ellingson, 1999: Cumulus cloud formulations for longwave radiation calculations. J. Atmos. Sci., 56, 837-851.

Han., D. and R. G. Ellingson, 2000: An experimental technique for testing the validity of cumulus cloud parameterizations for longwave radiation calculations. J. Appl. Meteor., 39, 1147-1159.

Killen, R. G., and R. G. Ellingson, 1994: The effects of shape and spatial distribution of cumulus clouds on longwave irradiance. J. Atmos. Sci., 51, 2123-2136.

Soden, B., S. Tjemkes, J. Schmetz, R. Saunders, J. Bates, R. Ellingson, R. Engelen, L.Garand, D. Jackson, G. Jedlovec, T. Kleespies, M. Koenig, D. Randel, P. Rayer, E. Salathe, D. Schwarzkopf, N. Scott, B. Sohn, S. de Souza-Machado, L. Strow, D.Tobin, D. Turner, P. van Delst, and T. Wehr, 2000: An intercomparison of radiation codes for retrieving upper tropospheric humidity in the 6.3-micron band: A report from the 1st GVaP Workshop. Bull. Amer. Meteor. Soc., 81, 797-808.

Stephens, G. L., R. G. Ellingson, J. Vitko, W. Bolton, T. P. Tooman, F. P. J. Valero, P. Minnis, P. Pilewski, G. S. Phipps, S. Sekelsky, J. R. Carswell, S. D. Miller, A. Benedetti, R. B. McCoy, R. F. McCoy, A. Lederbuhr, R. Bambha, 2000: The Department of Energy’s Atmospheric Radiation Measurement (ARM) Unmanned Aerospace Vehicle (UAV) Program. Bull. Amer. Meteor. Soc., 81, 2915-2937.

Takara, E. And R. G. Ellingson, 1996: Scattering Effects on Longwave Fluxes in Broken Cloud Fields. J. Atmos. Sci., 53, 1464-1476.

Takara, E. and R. G. Ellingson, 1999: Broken cloud field longwave scattering effects. J. Atmos. Sci., 57, 1298-1310.

Tobin, D. C., F. A. Best, P. D. Brown, S. A. Clough, R. G. Dedecker , R. G. Ellingson, R. K. Garcia, H. B. Howell, R. O. Knuteson, E. J. Mlawer, H. E. Revercomb, J. F. Short, P. F. W van Delst, and V. P. Walden, 1998: Spectral radiance observations at the SHEBA Ice Station: Water vapor continuum measurements from 17-26 $\mu \mathrm{m}$. J. Geophys. Res., 104, D2, 2081-2092. 
Turner, D. D., D. C. Tobin, S. A. Clough, P. D. Brown, R. G. Ellingson, E. J. Mlawer, R. O. Knuteson, H. E. Revercomb, T. R. Shippert, W. L. Smith, and M. Shepard, 2004: The QME AERI LBLRTM: A closure experiment for downwelling high spectral resolution infrared radiance. J. Atmos. Sci., In press.

Valero, F. P. J., S. K. Pope, R. G. Ellingson, A. W. Strawa, and J. Vitko Jr., 1996: Determination of clear-sky radiative flux profiles, heating rates, and optical depths using unmanned aerospace vehicles as a platform. J. Atmos. Ocean. Tech., 13, 1024-1030.

Walden, V. P., S. G. Warren, F. J. Murcray, R. G. Ellingson, 1997: Infrared radiance spectra for testing radiative transfer models in cold and dry atmospheres: Test cases from the Antarctic plateau, Bull. Amer. Meteor. Soc., 78, 2246-2247.

Warner, J. X., and R. G. Ellingson, 2000: A new narrow band radiation model for water vapor absorption. J. Atmos. Sci., 57, 1481-1496.

\section{b. Ph.D. Dissertations}

Han, D., 1996: Studies of Longwave radiative Transfer Under Broken Cloud Conditions: Cloud parameterizations and Validations, Ph.D. Dissertation, University of Maryland, College Park, MD, 163 pp..

Warner, J., 1997: A New Longwave Radiation Model For Application to Atmospheric Problems, , Ph.D. Dissertation, University of Maryland, College Park, MD, 198 pp..

Mr. Yingtao Ma, 2004: Longwave Radiative Transfer Through 3d Cloud Fields: Testing of The Probability of Clear Line of Sight Models with ARM Cloud Observations, University of Maryland, College Park. 174pp.

Ms. Ileana Musat, 2004: Short Term Variability of Atmospheric Extinction during the night under clear-sky conditions investigated by broadband stellar photometry. University of Maryland, College Park.

\section{c. M.S. Scholarly papers}

Arsky, N. 1994: Optimization of long wave radiation codes for global climate predictions. University of Maryland, College Park, MD.

Armstrong, M., 2000: Comparison of MM5 Forecast Shortwave Radiation with Data Obtained from the Atmospheric Radiation Measurement Program, M.S. Scholarly Paper, University of Maryland, College Park, MD, 22pp. Available upon request.

Cheng, Z., 1999: Broken Cloud Observations and Parameterizations for Longwave Radiation, M.S. Scholarly Paper, University of Maryland, College Park, MD, 42pp. Available upon request.

Musat, I., 2000: The Use of the ARM WSI to Estimate the Atmospheric Optical Depth at Night, M.S. Scholarly Paper, University of Maryland, College Park, MD, 32pp. Available upon request.

Rocque, K., 1995: Parallel computing in atmospheric models. University of Maryland, College Park, MD.

Shi, B., 1998: Comparison of Aircraft Observed with Calculated Downwelling Solar Fluxes during ARESE, M.S. Scholarly Paper, University of Maryland, College Park, MD, 20pp. Available upon request. 
Wonsick, M., 1995: An Intercomparison of Diagnostic and Prognostic Techniques for Estimating Cloudiness in Numerical Weather Prediction Models. University of Maryland, College Park, MD. Available upon request.

\section{d. Reports and extended Abstracts}

Baer, F., 1993: Longwave radiation algorithms in global climate modeling. In "Clouds and Radiation in GCMs", ed. E. Källén, Department of Meteorology, Stockholm University, ISSN 0349-0467, October 1993, pp. 13-19.

Baer, F., 1993: Radiative Heating in Global Climate Models. Proceedings of the 18th Annual Climate Diagnostics Workshop, Boulder, CO, 1-4 Nov. 1993, DOC/NOAA/ NWS/CAC, pp. 142-145.

Baer, F., N. Arsky, K. Rocque, 1994: Radiation Impacts on Global Climate Models. Proceedings of the fourth ARM Science Team Meeting, San Diego, CA, 28 Feb.- 3 Mar. 1994, DOE/OER/OHER/ESC, CONF-940277, pp. 85-89.

Baer, F., N. Arsky, K. Rocque, 1995: Radiative Heating in Global Climate Models. Proceedings of the fifth ARM Science Team Meeting, San Diego, CA, 20-23 March, 1995, DOE/OER/OHER/ESC.

Ellingson, R. G., and F. Baer, 1993: A study of longwave radiation codes for climate studies: Validation with ARM observations and tests in general circulation studies. Proceedings of the 2nd ARM Science team Meeting, CONF-9110336, UC-402, U.S. Dept. Energy, Washington, DC, 1-5.

Ellingson, R. G., 1993: Radiation parameterizations in climate models: Comparison of calculations with observations from the Spectral Radiation experiment (SPECTRE). In Clouds and Radiation in GCM's, E. Kallen Ed., Proceedings from the workshop held at the Stockholm University, Sweden, 24-26 May 1993, ISSN 0349-0467, Dept. Of Meteorology, Stockholm University, Stockholm, 29-32.

Ellingson, R. G., W. J. Wiscombe, J. DeLuisi, H. Melfi, and W. Smith, 1993: Calibration of radiation codes in climate models: Comparison of calculations with observations from the spectral radiation experiment (SPECTRE). FIRE Cirrus Science Results 1993, NASA Conference Publication 3238, NASA Langley Research Center, Hampton, VA, 181-184.

Ellingson, R. G., 1993: Atmospheric Radiation Measurement (ARM) Program: Project description and preliminary results. In Atmospheric Radiation, K. Stamnes, Ed., Proc. SPIE 2049, 102-106.

Takara, E., and R. G. Ellingson, 1994: Monte Carlo simulations of infrared radiative transfer through broken cloud fields. Proceedings of the Eight Conference on Atmospheric Radiation, American Meteorological Society, Boston, MA, 364-365.

Killen, R. and R. G. Ellingson, 1994: Sensitivity of atmospheric heating rate to cloud geometry and spatial distribution. Proceedings of the Eight Conference on Atmospheric Radiation, American Meteorological Society, Boston, MA, 510.

Ellingson, R. G., Suhung Shen, W. J. Wiscombe, J. DeLuisi, V. Kunde, H. Melfi, D. Murcray, and W. Smith, 1994: The Spectral Radiation Experiment (SPECTRE): An overview clear-sky observations and validation of line-by-line models. Proceedings of the Eight Conference on Atmospheric Radiation, American Meteorological Society, Boston, MA, 241-242. 
Ellingson, R. G., and F. Baer, 1994: A study of longwave radiation codes for climate studies: Validation with ARM observations and tests in general circulation studies- An update. Proceedings of the 3rd ARM Science team Meeting, CONF-9303112, UC-402, U.S. Dept. Energy, Washington, DC, 1-10.

Ellingson, R. G., 1995: Observations for Validating Radiative Transfer Parameterizations. Proceedings of the ECMWF Seminar on Parameterization of Sub-Grid Scale Physical Processes, European Center for Medium Range Weather Forecasts (ECMWF), Reading, U.K., 5 - 9 September 1994, ECMWF, Reading, UK, 3-14.

Ellingson, R. G., J. A. Curry, K. Stamnes, J. E. Walsh, B. D. Zak, 1995a: Overview of North Slope of Alaska/Adjacent Arctic Ocean Science Issues. Proceedings of the Fourth ARM Science Team Meeting, CONF-940277, UC-402, U.S. Dept. Energy, Washington, DC, 31-38. Also submitted to the J. Climate, July 1994.

Ellingson, R. G., S. Shen, and J. Warner, 1995b: Calibration of radiation codes used in climate models: Comparison of clear-sky calculations with observations from the Spectral Radiation Experiment and the Atmospheric Radiation Measurement Program. Proceedings of the 4th ARM Science team Meeting, CONF-940277, UC-402, U.S. Dept. Energy, Washington, DC, 47-53.

Ellingson, R. G., 1995: A Review of Parameterization Schemes for Radiative Transfer. Proceedings of the ECMWF Seminar on of Sub-Grid Scale Physical Processes, European Center for Medium Range Weather Forecasts (ECMWF), Reading, U.K., 5 - 9 September 1994, ECMWF, Reading, UK, 23-31.

Ellingson, R. G., 1998: The State of the ARM-IRF Accomplishments through 1997. In Proceedings of the Eighth Annual ARM Science Team Meeting, Ed. by N. Burleigh and D. Carrothers, U.S. Department of Energy, Richland, WA.

Ellingson, R. G., 1999: Thermal Radiative Transport in Clouds. Proceedings of the International Workshops on Intercomparison of 3-dimensional Radiation Codes:I3RC-99 - First Workshop: 17 - 19 November, 1999, Tucson, AZ.

Ellingson, R. G., 2000: The ARM Instantaneous Radiative Flux (IRF) Working Group in 2000: A Summary of Accomplishments, Strengths, Weaknesses, and Ideas for Future Activities. White paper for the ARM Science team executive Committee, July 2000. Available at http://www.arm.gov/docs/research.html\#vision2000/

Ellingson, R. G., and E. E. Takara, 1999: MDTERP MarylanD TErrestial Radiation Package: A Narrow-Band Longwave Radiation Model with a Graphical User Interface. Proceedings of the EUMETSAT 2000 Users Meeting, 469-476.

Ellingson, R. G., and E. E. Takara, 1999: MDTERP - A Narrowband Longwave Radiation Model With a Graphical User Interface. In Proceedings of the Ninth Annual ARM Science Team Meeting, Ed. by N. Burleigh and D. Carrothers, U.S. Department of Energy, Richland, WA.

Ellingson, R. G., and S. Shen, 1998: Comparisons of Surface Longwave Radiation Between Line-by-Line Radiative Transfer Model and Atmospheric Emitted Radiance Interferometer Observations from the Atmospheric Radiation Measurement Program. In Proceedings of the Seventh Atmospheric Radiation Measurement (ARM) Science Team Meeting, CONF-970365, US Department of Energy, Washington, D.C. 
Ellingson, R. G., and T. Tooman, 1997: ARM UAV Science and Experiment Plan. Program Director Office, Global Climate Change and Remote Sensing Office, Sandia National Laboratories, Livermore, CA, 178 pp.

Han, D., and R. G. Ellingson, 1997: A Test of the Validity of Cumulus Cloud Parameterizations for Longwave Radiation Calculations. In Proceedings of the Sixth Atmospheric Radiation Measurement (ARM) Science Team Meeting, CONF-9603149, US Department of Energy, Washington, D.C.

Han, D., and R. G. Ellingson, 1998: A Test of the Validity of Cumulus Cloud Parameterizations for Longwave Radiation Calculations. In Proceedings of the Seventh Atmospheric Radiation Measurement (ARM) Science Team Meeting, CONF-970365, US Department of Energy, Washington, D.C.

Ma, Y., and R. G. Ellingson, 2003: Testing the Probability of Clear Line of Sight Models with ARM Observations. In Proceedings of the Thirteenth ARM Science Team Meeting, Broomfield, Colorado, March 31-April 4, 2003, 12 pp. See http://www.arm.gov/publications/proceedings/conf13/author.stm\#m

Melfi, S. H., D. O' C. Starr, D. Whiteman, R. G. Ellingson, R. A. Ferrare, and K. D. Evans, 1996: Raman Lidar Measurements of Water Vapor and Aerosols During the Atmospheric Radiation Measurement (ARM) Remote Cloud Sensing (RCS) Intensive Observation Period (IOP). In Proceedings of the Fifth Atmospheric Radiation Measurement (ARM) Science Team Meeting, CONF-9503140, US Department of Energy, Washington, D.C.

Melfi, S. H., K. D. Evans, R. A. Ferrare, B. Demoz, G. Schwemmer, D. Whiteman, D. O.'C Starr, and R. G. Ellingson, 1998: Scanning Raman Lidar Measurements of Water Vapor and Aerosols During the Tropical Aerosol Radiative Forcing Observational Experiment and the Water Vapor Intensive Operations Period. In Proceedings of the Seventh Atmospheric Radiation Measurement (ARM) Science Team Meeting, CONF-970365, US Department of Energy, Washington, D.C.

Melfi, S. H., R. A. Ferrare, K. D. Evans, Whiteman, D. O'C, Starr, G. Schwemmer, R. G. Ellingson, E. Browell, W. Feltz, and W. L. Smith, 1997: Raman Lidar Measurements of Aerosols and Water Vapor. In Proceedings of the Sixth Atmospheric Radiation Measurement (ARM) Science Team Meeting, CONF-9603149, US Department of Energy, Washington, D.C.

Musat, I. C., 2003: Photometric Variations as Small Perturbations in Aerosol Content. In Proceedings of the Thirteenth ARM Science Team Meeting, Broomfield, Colorado, March 31-April 4, 2003, 3 pp. See http://www.arm.gov/publications/proceedings/conf13/author.stm\#m

Shen, S., and R. G. Ellingson, 1997: Comparison of Recalibrated Atmospheric Emitted Radiance Interferometer Observations with Line-by-Line Radiative Transfer Model Calculations. In Proceedings of the Sixth Atmospheric Radiation Measurement (ARM) Science Team Meeting, CONF-9603149, US Department of Energy, Washington, D.C.

Takara, E., and R. G. Ellingson, 1995: Monte Carlo simulations of infrared radiative fluxes through broken scattering cloud fields. Proceedings of the Fourth ARM Science Team Meeting, CONF-940277, UC-402, U.S. Dept. Energy, Washington, DC, 31-38.

Takara, E .E., and R. G. Ellingson, 1996: Longwave Scattering Effects on Fluxes in Broken Cloud Fields. In Proceedings of the Fifth Atmospheric Radiation Measurement (ARM) Science Team Meeting, CONF-9503140, US Department of Energy, Washington, D.C. 
Takara, E. E., and R. G. Ellingson, 1997: Window-Region Longwave Fluxes: Accounting for Cloud Scattering. In Proceedings of the Sixth Atmospheric Radiation Measurement (ARM) Science Team Meeting, CONF-9603149, US Department of Energy, Washington, D.C.

Takara, E. E., and R. G. Ellingson, 1998: Broken Field Approximations in the Longwave. In Proceedings of the Eighth Annual ARM Science Team Meeting, Ed. by N. Burleigh and D. Carrothers, U.S. Department of Energy, Richland, WA.

Takara, E. E., and R. G. Ellingson, 2000: Use of ARM observations to estimate broken cloud effects on terrestrial radiation. In proceedings of the International Radiation Symposium, St. Petersburg, Russia, 24-29 July 2000.

Vitko, J. Jr., T. P. Tooman, and R. G. Ellingson, 1998: Hawaii '98: A Tropical Cloud Mission. In Proceedings of the Eighth Annual ARM Science Team Meeting, Ed. by N. Burleigh and D. Carrothers, U.S. Department of Energy, Richland, WA.

Vitko, J. Jr., T. P. Tooman, and R. G. Ellingson, 1999: ARM -UAV: The Next Phase. In Proceedings of the Ninth Annual ARM Science Team Meeting, Ed. by N. Burleigh and D. Carrothers, U.S. Department of Energy, Richland, WA.

Warner, J. X., and R. G. Ellingson, 1997: A narrow band longwave radiation model based on parameters fitted to line-by-line radiative transfer models, In Proceedings of the Sixth Atmospheric Radiation Measurement (ARM) Science Team Meeting, CONF--9603149, US Department of Energy, Washington, D.C.

Warner, J. X., and R. G. Ellingson, 1998: A Narrow Band Longwave Radiation Model Based on Parameters Fitted to Line-by-Line Radiative Transfer Model. In Proceedings of the Seventh Atmospheric Radiation Measurement (ARM) Science Team Meeting, CONF-970365, US Department of Energy, Washington, D.C.

\section{Presentations (March 1996 - April 2004)}

1996

ARM Science Team Meeting, San Antonio, TX, 3-7 March 1996

Baer, F., J. Mao and Y. Shen, 1996: Response of global climate models to radiative forcing.

Shen, S. and R. G. Ellingson, 1996: Comparison of recalibrated AERI observations with LBLRTM calculations.

Sowle, D., M. Frolli, S. More, C. Gautier, and R. G. Ellingson, 1996: Clear-sky shortwave absorption during ARESE.

Warner, J. X., and R. G. Ellingson, 1996: A narrow band longwave radiation model based on parameters fitted to LBLRTM.

Wiscombe, W. J., S. Shen, and R. G. Ellingson, 1996: Compilation of the SPECTRE CD.

\section{International Radiation Symposium, Fairbanks, AK, 19-24 Aug. 1996}

Ellingson, R. G., J. Vitko, T. Tooman, and W. Bolton, 1996: The ARM-UAV Program: Project description and first results. (invited)

Ellingson, R. G., and S. Shen, 1996: Progress toward validation of radiation models for climate studies: comparisons of observations with calculations. (oral) 
Han, D. and R. G. Ellingson, 1996: A Test of the Validity of Cumulus Cloud Parameterizations for Longwave Radiation Calculations. (Poster)

Takara, E., and R. G. Ellingson, 1996: Window region longwave fluxes, accounting for cloud scattering. (Poster)

Baer, F., Y. Shen, J. Mao and R. Ellingson, Response of global climate models to radiative forcing. (oral)

Takara, E. E. and R. G. Ellingson, 1996, Window region longwave fluxes, accounting for cloud scattering. (Poster)

Other 1996 presentations

Ellingson, R. G., 1996: A Review of Parameterization Schemes for Radiative Transfer. Presented at the International Workshop on Tropical Limited Area Modelling (sponsored by the International Center for Theoretical Physics and the World Meteorological Organization), 26-30 October, Trieste, Italy. (150 minutes of lectures, 150 minutes computer laboratory).

Ellingson, R. G., 1996: The ARM-UAV Program: Project Description and First Results. Presented at the NASA Goddard weekly seminar series, Dec. 18, Greenbelt, MD.

1997

Review of the ARM Program by the Washington Area Group, Washington, DC, Jan. 1997

Ellingson, 1997: The Development of the ARM program in 1989-90.

Ellingson, 1997: Accomplishments of the ARM-UAV Program 1994-1997.

9th Conference on Atmospheric Radiation, Long Beach, CA, 3-7 Feb. 1997.

Ellingson, R. G., 1997: The State of the Science Regarding Calculation of Longwave Radiation Quantities (invited paper).

Han, D. and R. G. Ellingson, 1997: A Test of the Validity of Cumulus Cloud Parameterizations for Longwave Radiation Calculations (oral and poster).

Shen, S.-H., and R. G. Ellingson, 1997: Comparisons of surface longwave radiance between LBLRTM and AERI observations from ARM (poster).

Warner, J., and R. G. Ellingson, 1997: A Narrow Band Longwave Radiation Model Based on Parameters Fitted to LBLRTM (poster).

ARM Science Team Meeting, San Antonio, TX, 3-7 March 1997

Ellingson, R. G., 1997: The ARM-UAV Program: The year in review. Presented at both the ARM-UAV Science Team and the ARM science team meetings, March 1997.

Takara, E. and R. G., 1997: Ellingson: Broken Cloud Field Longwave Scattering Effects

Han, D. and R. G. Ellingson, 1997: A test of the validity of cumulus cloud parameterizations for longwave radiation calculation.

Warner, J. X. and R.G. Ellingson, 1997: A narrow band longwave radiation model based on parameters fitted to LBLRTM.

Shen., S. and R.G. Ellingson, 1997: Comparisons of surface longwave radiance between LBLRTM and AERI Observations from ARM

Spring AGU Meeting, Baltimore, MD, May 1997

Ellingson, R. G., 1997: The Atmospheric Radiation Measurements (ARM) Program: Description and Progress to Date (invited.) 
Joint Assemblies of IAMAS-IAPSO, Melbourne, Australia, July 1997

Han, D. and R. G. Ellingson, 1997: A Test of the Validity of Cumulus Cloud Parameterizations for Longwave Radiation Calculations (oral).

Ellingson, R. G. and S. Shen, 1997: Progress Toward Validation of Radiation Models for Climate Studies: Comparisons of Observations with Calculations (oral).

Ellingson, R. G., J. Vitko, T. Tooman, W. Bolton, D. Sowle, F. Valero, and S. Pope, 1997: The ARM-UAV program: project description and first results (oral).

7th International Workshop on Atmospheric Science from Space Using Fourier Transform Spectrometry, Oberpfaffenhofen, Germany, 12 - 14 May 1997

Ellingson, R. G. and S. Shen, 1997: Comparisons of surface longwave radiances between LBLRTM and AERI observations from ARM. (invited).

1998

ARM Science Team Meeting, Tucson, AZ, 23-27 March 1998

Baer, F., and R. G. Ellingson, 1998: Regional (Subgrid) Scale Variability and Sensitivity of Longwave Radiative Heating.

Ellingson, R. G., 1997: The State of ARM IRF: Accomplishments through 1997 (invited).

Han D., and R. G. Ellingson, 1998: Comparisons of Measurements of Cloud Lower Boundaries by the MPL, BLC, MMCR, BBSS and AERI.

Takara, E. E. and R. G. Ellingson, 1998: Broken cloud field approximations in the longwave.

Tobin, D. C., R. O. Knuteson, H. E. Revercomb, V. P. Walden, S. A. Clough, E. J. Mlawer, and R. G. Ellingson, 1998: AERI-ER at the SHEBA ice station: Far Infrared Water Vapor Continuum Measurements.

Upper Tropospheric Water Vapor Workshop, Darmstadt, Germany,2-4 June 1998

Ellingson, R. G., and R. Tian, An Experimental Operational Program to Obtain Longwave Radiation Budget Parameters from the NOAA Operational Satellites: A Status Report and Summary Data Products (invited).

University of Maryland Baltimore County, 17 November 1998

Ellingson, R. G., Development, Validation and Application of a Detailed Longwave Radiation Model for Atmospheric Studies (invited).

1999

ARM Science Team Meeting, San Antonio, TX, 3-7 March 1999

Cheng, Z. and R. G. Ellingson: Use of the MMCR to Estimate Finite-Size Cloud Effects on Longwave Radiation.

Ellingson, R. G., and E. Takara: MDTERP - A Narrowband Longwave Radiation Model With a Graphical User Interface.

Ma, Y. and R. G. Ellingson: Evidence for Aerosol Effects on AERI Clear-sky Radiance at the SGP.

Takara, E. and R. G. Ellingson: Longwave Broken Cloud Approximations Allowing for Cloud Transmission.

Vitko, J. Jr., T. P. Tooman, and R. G. Ellingson: ARM -UAV: The Next Phase. 
10 th Conference on Atmospheric Radiation, Madison, WI, 28 June - 1 July 1999

Takara, E. and R. G. Ellingson: Longwave Broken Cloud Approximations Allowing for Cloud Transmission (poster)

Joint Assemblies of IAMAS-IAPSO, Birmingham, United Kingdom, July 1999

Ellingson, R. G., D. Han, and Z. Cheng: Validation of Cumulus Cloud Parameterizations for Longwave Radiation (oral).

Ellingson, R. G.: The Accuracy of Longwave Radiation Calculations for Earth-Atmosphere Applications (oral).

Ellingson, R. G., T. Tooman, T., J. Shields, D. Sowle, G. Christensen, and S. Moore, 1999:

Automatic Determination of Daytime and Nighttime Cloud Fraction (oral).

International Workshops on Intercomparison of 3-dimensional Radiation Codes: 17 - 19 November 1999, Tucson, AZ.

Ellingson, R. G., 1999: Thermal Radiative Transport in Clouds (invited).

2000

ARM Science Team Meeting, San Antonio, TX, 13-17 March 2000

Takara, E. E. and R. G. Ellingson, 2000: Validation of longwave cumulus cloud parameterizations using ARM data

Ma, Y. and R. G. Ellingson, 2000: Probability of Clear Line-of-Sight Determined from the VTLC and WSI

Ellingson, R. G. and E. E. Takara, 2000: The Maryland Terrestrial Radiation Package (MDTERP) - A Narrow-Band Longwave Radiation Model with a Graphical User Interface.

IEEE International Geoscience and Remote Sensing Symposium (IGARSS), Honolulu, HI, 22-26 July 2000

Ellingson, R. G. and the ARESE II Science Team, 2000: The ARM Enhanced Shortwave Experiments (ARESE): Description and Initial Results (invited).

International Radiation Symposium, St Petersburg, Russia, 24-29 July 2000

Takara, E. E. and R. G. Ellingson, 2000: Use Of ARM Observations To Estimate Broken Cloud Effects On Terrestrial Radiation (poster).

The EUMETSAT Meteorological Satellite Data Users' Conference, Bologna, Italy, 29 May to 2 June 2000

Ellingson, R. G. and E. E. Takara, 2000: The Maryland Terrestrial Radiation Package (MDTERP) - A Narrow-Band Longwave Radiation Model with a Graphical User Interface (poster).

2001

ARM Science Team Meeting, San Antonio, TX, 19-23 March 2001

Armstrong, M. A., R. G. Ellingson, H.-T. Lee, 2001: Comparison of MM5 Forecast Shortwave Radiation with ARM SGP Data

Ellingson, R. g., and the ARESE II Science Team, 2001: ARESE II (ARM Enhanced Shortwave Experiment): Description and Initial Results (invited) 
Ma, Y. and R. G. Ellingson, 2000: Probability of Clear Line-of-Sight Determined from the TLCV and WSI.

Musat, I. C. and R. G. Ellingson, 2001: The Use of the ARM WSI to Estimate the Atmospheric Optical Depth at Night.

Takara, E. E. and R. G. Ellingson, 2000: Evaluating the accuracy of parameterizations for effective cloud fractions for small cumulus clouds in the longwave using ARM data.

IAMAS, Innsbruck, Austria 11-18 July 2001

Ellingson, R. G., E. E. Takara, and Y.-T. Ma, 2001: Evaluating the Accuracy of Parameterizations for Effective Cloud Fractions for Small Cumulus Clouds in the Longwave using ARM Data.

Ellingson, R. G., and I. Musat, 2001: The Use of the ARM WSI to Estimate the Atmospheric Optical Depth at Night.

Ellingson, R. G., and the ARESE II Team, 2001: The ARM Enhanced Shortwave Experiment ll (ARESE ll) - Experiment Description and Initial Results (invited paper).

2002

ARM Science Team Meeting, St. Petersburg, FL, 8-12 April 2002.

Ma, Y. and R. G. Ellingson, 2002: On the uncertainty of inferring absolute cloud fraction from time series of narrow field of view observations, poster presentation at the ARM Science Team Meeting, St. Petersburg, FL, April 2002.

Musat, I. and R. G. Ellingson, 2002: Analysis interface for nighttime aerosol optical depth assessment with ARM WSI, poster presentation at the ARM Science Team Meeting, St. Petersburg, FL, April 2002.

2003

ARM Science Team Meeting, Broomfield, Colorado, 31 March - 4 April 2003

Ma, Y. and R. G. Ellingson, 2003: Testing of probability of clear line of sight models with arm observations.

Musat, I. and R. G. Ellingson, 2003: Photometric variations as small perturbations in aerosol content.

2004

ARM Science Team Meeting, Albuquerque, New Mexico, 22 - 26 March 2004

Musat, I. C., and Ellingson, R. G., 2004: Heterochromatic Extinction During Nighttime at the SGP.

Ma, Y. and Ellingson, R. G., 2004: Inferring Domain-Averaged Cloud Properties from the ARM Observations and Testing the PCLOS Models. 